\title{
Analysis of Distributed Generation Allocation and Sizing in Distribution Systems via a Multi-objective Particle Swarm Optimization and Improved Non dominated Sorting Genetic Algorithm-II
}

\author{
Monica Deshmukh \\ Sagar Institute of Research, \\ Technology and Science \\ Bhopal, India
}

\author{
Neeti Dugaya \\ Sagar Institute of Research, \\ Technology and Science \\ Bhopal, India
}

\begin{abstract}
In the recent era the distributed generation (DG) has a lot of power setups operation. The basic advantage of distribution generation includes reduce Power loss, eco; improve voltage, system upgrading postponement. Also it's more reliable and environment friendly. We will compare optimization approach with the hybrid particle swarm optimization (HPSO) and the No dominated sorting Genetic Algorithm (NSGA-II).in this study for determining the optimal DGunit's size, power factor, and location in to reduce the real power loss in the whole system with HPSO algorithm we can find the solution considering maximization of system load and relative minimum power losses. The second algorithms is improved no dominated sorting genetic algorithm II (INSGAII) with the help of which multi objective planning problem is resolved is also described here. Sample radial distribution feeder systems are compared here to find the validity of both above mentioned algorithm. In this way updating of the two parameters to find the most effective values has a higher chance of success as compared to any other metaheuristic methods.
\end{abstract}

\section{Keywords}

Distributed generation (DG), HPSO, INSGA-II, Metaheuristic optimization algorithms, Power losses reduction

\section{INTRODUCTION}

Though the practical application is difficult the DG unit application still has been preferred by the researchers Due to its several advantages. The advantages comprise the benefits such as eco-friendly-ness improves voltage, system upgrading postponing and reduced power loss. The final optimal output is impacted by the social economic and political factor in this method. This method can be interpreted as mixed integer nonlinear optimization problem. Generally maximize the voltages of the system and reduce the cost and power loss. The solution may vary from one application to another. Hence, if more objectives and constraints are included in the algorithm, than more data is required. Due to which the implementation becomes more difficult. Tools like genetic algorithm (GA), evolutionary programming (EP), and particle swarm optimization (PSO) are very useful and still evolving to solve different DG unit problem. Some of these techniques have been modified to improve their solution performance and reduce the limitation most of these tools have different parameters which needs to be tuned. A methodology for evaluating the impact of DG-units on power loss, reliability, and voltage profile of distribution networks was presented in reference [1]. The DG unit represented here as a PV bus which is different from what radial distribution feeders are designed for. It implies that on-line systems including DGunits can be more reliable interruption situations to keep customers supplied. It states that the simplest representation of DG-units operating in parallel with the system, especially in radial feeders, is as negative active and reactive power injections, independent of the system voltage at the terminal bus. When using multiple DG-units as PV configurations, it is unrealistic to manage these DG-units as available for dispatching because they may not be controlled by the utility. According to the IEEE standard, distributed resources (DR or DG) are not preferred to regulate the voltage (i.e., PV-bus) at the point of installation [2].

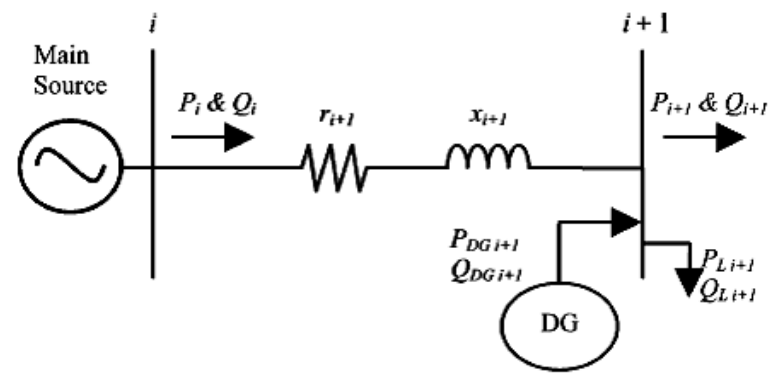

Fig 1: Single-line diagram of a two-bus system with and without reactive power injection

With the insertion of DG unit application the basic assumption that the system was design for one way power flow is violates which can cause disruption in the distribution operation causing islanding and protection disturbances; it can also upset voltage regulation, and can cause power quality issues. Therefore it should be employed very carefully. This system flows the utility voltage and injects a constant amount of reactive and real power [3]. We can reduce search space significantly by reducing the DG unit size. However dispatching it can cause operational problem in the distribution feeders. An algorithm is shown in figure [4]. For maximizing the load supply costs reduction and operational schedules by exploiting EP for all feeder loads level. On The basis of maximum cost reduction, the optimal solution can be selected by evaluating the cost of DG-unit supply circumstances based on the base case in figure [5] a method to calculate the optimal DG-unit size is described. In addition, an approximate loss formula to identify the optimal DG-unit placement was suggested. The remainder of the paper is organized as follows. Section III presents the mathematical formulations of the problem, Section IV explains the ABC algorithm, Section $\mathrm{V}$ describes the ABC algorithm in solving the DG-unit application, Section VI includes results and discussion, and Section VII outlines the conclusions. 


\section{PROBLEM FORMULATION}

\subsection{DG Owner's Cost and Profit Functions}

For an investor of DG the main purpose is to get maximum profit irrespective of as power grid operational conditions. The cost and profit for DG owner is described as follows.

1) Investment Cost: includes costs spent on unit construction, installing cost and essential equipment cost for every unit of generation. It is described in the below equation:

$\mathrm{C}_{\text {investment }}=\sum_{\mathrm{i}=1}^{\mathrm{N}_{\mathrm{DG}}} \mathrm{P}_{\mathrm{DG}, \mathrm{i}} \times$ Cost $_{\text {inv }}$

The above equation denotes the active power generated by the unit.

2) Operational Cost: this cost includes the expanses on fuel generation, and other operating costs below equation described this cost.

$\mathrm{C}_{\text {operational }}=\sum_{\mathrm{j}=1}^{\mathrm{N}_{\mathrm{N}}} \sum_{\mathrm{i}=1}^{\mathrm{N}_{\mathrm{DG}}} \mathrm{P}_{\mathrm{DG}, \mathrm{i}} \times \mathrm{CF}_{\mathrm{i}} \times \mathrm{T}_{\mathrm{h}} \times$ Cost $_{\text {oper }} \times$ $\left(\frac{1+\text { INF_R R }_{1}}{1+\mathrm{INT}_{2} \mathrm{R}}\right)^{\mathrm{j}}$

Where denotes the year index.

3) Maintenance Cost: This cost includes the expenses incurred on repairing, renewing and restoring the equipment whenever required. This cost is calculated as per below equation.

$\mathrm{C}_{\text {maintanance }}=\sum_{\mathrm{j}=1}^{\mathrm{N}_{\mathrm{N}}} \sum_{\mathrm{i}=1}^{\mathrm{N}_{\mathrm{DG}}} \mathrm{P}_{\mathrm{DG}, \mathrm{i}} \times \mathrm{CF}_{\mathrm{i}} \times \mathrm{T}_{\mathrm{h}} \times$ Cost $_{\text {maint }} \times$ $\left(\frac{1+\text { INF_R }_{2}}{1+\text { INT_R }^{\mathrm{j}}}\right)^{\mathrm{s}}$

4) DG Owner's Income: The profit can be gained by selling the generated power to the DisCo as per the contract price. This income can be calculated as per below equation.

$\mathrm{IN}_{\mathrm{DG}}=\sum_{\mathrm{j}=1}^{\mathrm{N}_{\mathrm{Y}}} \sum_{\mathrm{i}=1}^{\mathrm{N}_{\mathrm{DG}}} \mathrm{P}_{\mathrm{DG}, \mathrm{i}} \times \mathrm{CF}_{\mathrm{i}} \times \mathrm{T}_{\mathrm{h}} \times \mathrm{Cost}_{\mathrm{DG}} \times\left(\frac{1+\mathrm{INF} \mathrm{F}_{\text {_R }}}{1+\mathrm{INT} \mathrm{R}}\right)^{\mathrm{j}}$

(4)

\subsection{Disco's Costs}

A part from on own profit the Disco also has to take into account the operational condition of the power grid like voltage profile and stability, branch current limits, customer security, and reliability. Hence, the DGs' sizes, contract prices and locations are the key factors in it. The DisCo's costs can be calculated as below.

1) Price of Purchasing Power From the DG Owner: It is based on the contract price. DisCo cost has already been calculated above as DG owner's income in equation (4). The DG owner gets profited by the Disco's purchasing power from him or her. Therefore they are strongly interconnected.

2) Cost of Buying Power from the Substation: The power, which is beyond the DG unit's capacities, should be bought by the DisCo from the substation. This power is computed by the following equation:

$\mathrm{P}_{\text {sub }, \mathrm{t}, \mathrm{j}}=\sum_{\mathrm{n}=1}^{\mathrm{N}_{\text {Bus }}} \mathrm{P}_{\mathrm{L}, \mathrm{n}, \mathrm{t}, \mathrm{j}}+\mathrm{P}_{\text {Loss }, \mathrm{t}, \mathrm{j}}-\sum_{\mathrm{i}=1}^{\mathrm{N}_{\mathrm{DG}}} \mathrm{P}_{\mathrm{DG}, \mathrm{i}}$

Where

$\mathrm{P}_{\text {Loss }, \mathrm{t}, \mathrm{j}}=\sum_{\mathrm{b}=1}^{\mathrm{N}_{\mathrm{b}}} \mathrm{r}_{\mathrm{b}} \times \mathrm{I}_{\mathrm{b}, \mathrm{t}, \mathrm{j}}{ }^{2}$

In (5) and (6), and refer to the bus and branch indices, respectively. Furthermore, is the time index referring to each hour of the day. Buying power from the substation is another cost that the DisCo should spend. The present value of this cost is

$\mathrm{C}_{\text {sub }}=\sum_{\mathrm{j}=1}^{\mathrm{N}_{\mathrm{Y}}} \sum_{\mathrm{t}=1}^{24} \mathrm{P}_{\text {sub }, \mathrm{t}, \mathrm{j}} \times \mathrm{T}_{\mathrm{d}} \mathrm{C}_{\mathrm{MWh}, \mathrm{P}} \times\left(\frac{1+\mathrm{INF} \mathrm{F}_{\mathrm{R}} \mathrm{R}}{1+\mathrm{INT} \mathrm{R}}\right)^{\mathrm{j}}$

It is obvious that the proper location and size of DGs can decrease power losses in the system and, consequently, it can impact the mentioned cost.

3) Customer Interruption Cost: Customer satisfaction and welfare are imperative in case of power failure in the power grid. Hence, the cost associated with them is added to the Discos' responsibility. On the basis of this fact, the customer interruption cost (CIC) in (8) is utilized to evaluate the present expense as shown below.

$\mathrm{CIC}=\sum_{\mathrm{j}=1}^{\mathrm{N}_{\mathrm{Y}}} \sum_{\mathrm{b}=1}^{\mathrm{N}_{\mathrm{b}}} \mathrm{C}_{\mathrm{int}} \times \lambda_{\mathrm{b}} \times \mathrm{L}_{\mathrm{b}} \times \sum_{\mathrm{k}=1}^{\mathrm{N}_{\mathrm{NS}}} \mathrm{P}_{\mathrm{L}, \mathrm{k}, \mathrm{j}} \times\left(\frac{1+\mathrm{INF} \_\mathrm{R}}{1+\mathrm{INT} \_\mathrm{R}}\right)^{\mathrm{j}}$

Where denotes the not-supplied loads index. According to (8), CIC is the calculation of the interruption cost based on the amount of energy which is not supplied (ENS) to the customers. It is the price of interruption in supplying the load during the repairing time varying on the type of loads (residential, commercial, or industrial)

\subsection{Objective Functions and Constraints}

In this section, the objective functions and their related constraints for solving this optimization problem are introduced. Three objectives are considered in the optimization model, which include: 1) reducing system line losses; 2) reducing voltage deviation; and 3) increasing voltage stability margin when DG units are considered in the distribution network (DN).

1) Minimization of Line Losses: The first objective is to minimize system line losses after DG injection into the distribution network. This objective function is as

$\operatorname{minf}_{1}(\mathrm{x})=\min \sum_{(\mathrm{i}, \mathrm{j}) \in \mathrm{B}} g_{\mathrm{ij}}\left(\mathrm{V}_{\mathrm{i}}^{2}+\mathrm{V}_{\mathrm{j}}^{2}-2 \mathrm{~V}_{\mathrm{i}} \mathrm{V}_{\mathrm{j}} \cos \theta_{\mathrm{ij}}\right)$

Where $B$ is the set of branches of network, and $(I, j) \in$ $\mathrm{B}$ denotes that $(\mathrm{I}, \mathrm{j}) \in$ are two nodes of a branch, and $\mathrm{Vi}$ and $\mathrm{Vj}$ are voltage magnitudes of nodes $\mathrm{i}$ and $\mathrm{j}$, respectively. $\mathrm{G}_{\mathrm{ij}}$ is the conductance between nodes $\mathrm{i}$ and $\mathrm{j}$. And $\theta \mathrm{ij}$ is the difference between nodal phase angles and,

2) Minimization of Voltage Deviation: The second objective is to minimize the voltage deviation between nodal voltage and specified voltage magnitude. Nodal voltage magnitude is an important indicator to evaluate system security and power quality (PQ). The minimization of voltage deviation can help guarantee a better voltage level in distribution power systems. The function can be written as

$\operatorname{minf}_{2}(x)=\min \sum_{i=1}^{N}\left(\frac{V_{i}-V_{i}^{\text {spec }}}{V_{i}^{\max }-V_{i}^{\min }}\right)^{2}$

Where $V_{i}$ is the voltage magnitude at the ith bus, and $V_{i}^{\text {spec }}$ is the specified voltage magnitude. $V_{i}^{\max }$ and $V_{i}^{\min }$ are the upper and lower limits at the iTh bus, respectively. $\mathrm{N}$ is the number of buses. The exponent in (10) is set to 2 in order to make the difference between the voltage in the ith node and the specified voltage non-negative.

3) Maximization of Voltage Stability Margin: The third objective is to maximize steady-state voltage stability margin. Voltage stability margin is the measure of the security level of the distribution system. Among different indices for voltage stability, a fast indicator of voltage stability, L-index, is 
chosen as the indicator for voltage stability index. L-index was presented by Kessel and Glavitsch [9], and developed by Jasmon and Lee [10]. The L-index of branch can be expressed as follows:

$L_{i j}=\frac{4\left[\left(P_{j} X_{i j}-Q_{j} R_{i j}\right)^{2}+\left(P_{j} R_{i j}-Q_{j} X_{i j}\right) V_{i}^{2}\right]}{V_{i}^{4}}$

Where $L_{i, j}$ indicates the extent of branch voltage stability. The branch voltage will be instable if the value of $L_{i, j}$ is large. Obviously, the voltage instability of the network is determined by the most instable branch, and its expression is as

$\mathrm{L}=\max \left(\mathrm{L}_{1}, \mathrm{~L}_{2}, \ldots, \mathrm{L}_{\mathrm{N}-1}\right)$

Where the L-index ranges from 0 (no load of system) to 1 (voltage collapse). The bus with the highest L-index will be the most vulnerable bus and, hence, this method helps identify the weak areas needing critical reactive power support in the system. In order to maximize the voltage stability margin, the corresponding function is as

$\operatorname{minf}_{3}(\mathrm{x})=\operatorname{minL}$

4) Constraints and Limitations: This optimization problem is subjected to various constraints as follows.

a) Bus Voltages and Branch Currents Limits: In this optimization problem, DGs' locations and sizes should be determined in such a way that bus voltages and branch currents remain in standard intervals during the planning period. These limitations are defined as follows:

$\mathrm{I}_{\mathrm{b}, \mathrm{t}, \mathrm{j}} \leq \mathrm{I}_{\mathrm{b}}^{\max }$

$\mathrm{V}^{\min } \leq \mathrm{V}_{\mathrm{n}, \mathrm{t}, \mathrm{j}} \leq \mathrm{V}^{\max }$

Where and are the minimum and maximum allowed amounts of voltage in each bus, respectively. Also denotes the maximum amount of current that can flow in each line according to the lines thermal limitations.

b) DG Capacity Limit: It should be assumed that the active and reactive capacity of each DG is limited to a specific interval as follows:

$\mathrm{P}_{\mathrm{DG}, \mathrm{i}}^{\min } \leq \mathrm{P}_{\mathrm{DG}, \mathrm{i}} \leq \mathrm{P}_{\mathrm{DG}, \mathrm{i}}^{\max }$

$\mathrm{Q}_{\mathrm{DG}, \mathrm{i}}^{\min } \leq \mathrm{Q}_{\mathrm{DG}, \mathrm{i}} \leq \mathrm{Q}_{\mathrm{DG}, \mathrm{i}}^{\max }$

In these inequalities...... and are the minimum and maximum amounts of active and reactive powers that can be generated by the DG unit.

c) Contract Price Limits: It is logical to say that the contract price between the DG owner and the DisCo is limited according to the electricity market conditions and this inequality can be expressed as follows:

$\mathrm{CP}_{\mathrm{DG}}^{\min } \leq \mathrm{CP}_{\mathrm{DG}} \leq \mathrm{CP}_{\mathrm{DG}}^{\max }$

Where and are the minimum and maximum amounts of the contract price that can be determined according to the market electricity price and other economic deliberations.

d) Power-Flow Constraints: It is necessary for active and reactive power injections to satisfy the power-flow equations

$\mathrm{P}_{\mathrm{n}}=\mathrm{V}_{\mathrm{n}} \sum_{\mathrm{m} \in \mathrm{N}} \mathrm{V}_{\mathrm{m}}\left(\mathrm{g}_{\mathrm{mn}} \operatorname{Cos}\left(\theta_{\mathrm{mn}}\right)+\mathrm{b}_{\mathrm{mn}} \operatorname{Sin}\left(\theta_{\mathrm{mn}}\right)\right)(19)$

$\mathrm{Q}_{\mathrm{n}}=\mathrm{V}_{\mathrm{n}} \sum_{\mathrm{m} \in \mathrm{N}} \mathrm{V}_{\mathrm{m}}\left(\mathrm{g}_{\mathrm{mn}} \operatorname{Sin}\left(\theta_{\mathrm{mn}}\right)-\mathrm{b}_{\mathrm{mn}} \operatorname{Cos}\left(\theta_{\mathrm{mn}}\right)\right)(20)$

e) DG Owner Capitalization Constraint: The amount of capitalization that the DG owner have enough money and stated by the following inequity:

$\mathrm{C}_{\text {investment }} \leq \mathrm{C}_{\text {investment }}^{\max }$

Where $C_{\text {investment }}^{\max }$ denotes the maximum affordable amount of capitalization from the DG owner's opinion.

f) Thermal limits:

$S_{i j}=\left|V_{i}^{2} G_{i j}-V_{i} V_{j}\left(G_{i j} \cos \theta_{i j}+B_{i j} \sin \theta_{i j}\right)\right| \leq S_{i j}^{\max }$

Where $P_{D G i}^{\min }, P_{D G i}^{\max }, Q_{D G i}^{\min }$, and $Q_{D G i}^{\max }$ are the lower/upper active and reactive generating unit limits of $D G$, respectively. $S_{i, j}^{\max }$ is the apparent power thermal limit of the circuit between bus and.

\subsection{Operational and Economic Indices}

In order to have a better evaluation of the operational condition of the power grid and the profitability of the contract between the DG owner and the DisCo from their own viewpoints, some operational and economic indices are presented as follows.

1) Operational Indices: In order to evaluate the operational state of the grid, some indices are introduced. For better evaluation, per-unit (p.u.) values of these indices are also calculated.

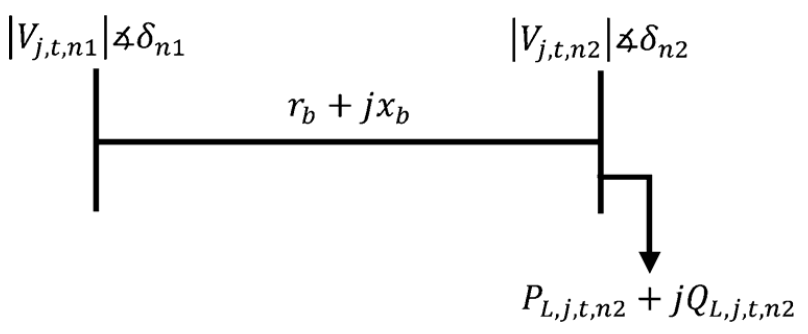

Fig 2: Representative branch of a radial distribution system

The numerators and denominators of these p.u. indices are the related values of the defined indices in the presence and absence of DGs in the grid.

a) Total Voltage Profile Index (TVPI): This index calculates the variation of all bus voltages from $\mathrm{V}_{\text {rated }}$ ( 1 p.u.). Since the flatter voltage profile is more appropriate, the total voltage profile index (TVPI) is considered as below [4]:

$$
\begin{aligned}
& \text { TVPI }=\sum_{\mathrm{j}=1}^{\mathrm{N}_{\mathrm{Y}}} \sum_{\mathrm{t}=1}^{24} \sum_{\mathrm{n}=1}^{\mathrm{N}_{\mathrm{Bus}}}\left|\mathrm{V}_{\text {rated }}-\mathrm{V}_{\mathrm{n}, \mathrm{j}, \mathrm{t}}\right|(23) \\
& \mathrm{TVPI}_{\text {p.u. }}=\frac{\mathrm{TVPI}_{\text {with } \mathrm{DG}}}{\mathrm{TVPI}_{\text {without } \mathrm{DG}}}
\end{aligned}
$$

b) Total Voltage Stability Index (TVSI): In radial distribution networks where each receiving node is fed by only one sending node, this index can be a good measure for evaluating voltage stability. According to Fig. 1, for all buses from two to, the stability index (SI) is calculated as follows [27]:

$$
\begin{aligned}
& \operatorname{VSI}_{\mathrm{j}, \mathrm{t}, \mathrm{n} 2}=\left|\mathrm{V}_{\mathrm{j}, \mathrm{t}, \mathrm{n} 1}\right|^{4}-4 \times\left(\mathrm{P}_{\mathrm{L}, \mathrm{j}, \mathrm{t,n} 2} \times \mathrm{x}_{\mathrm{b}}-\mathrm{Q}_{\mathrm{L}, \mathrm{j}, \mathrm{t,n} 2} \times \mathrm{r}_{\mathrm{b}}\right)^{2}- \\
& 4 \times\left(\mathrm{P}_{\mathrm{L}, \mathrm{j}, \mathrm{t}, \mathrm{n} 2} \times \mathrm{r}_{\mathrm{b}}+\mathrm{Q}_{\mathrm{L}, \mathrm{j}, \mathrm{t}, \mathrm{n} 2} \times \mathrm{x}_{\mathrm{b}}\right)^{2} \times\left|\mathrm{V}_{\mathrm{j}, \mathrm{t}, \mathrm{n} 1}\right|^{2}(25)
\end{aligned}
$$

The higher the VSI is for each bus, the better the stability of that relevant node shall be. The total voltage stability index (TVSI) and its per-unit value are described as

$\operatorname{TVSI}=\sum_{\mathrm{j}=1}^{\mathrm{N}_{\mathrm{Y}}} \sum_{\mathrm{t}=1}^{24} \sum_{\mathrm{n}=2}^{\mathrm{N}} \operatorname{VSI}_{\mathrm{j}, \mathrm{t}, \mathrm{n}}$ 


$$
\text { TVSI }_{\text {p.u. }}=\frac{\text { TVSI }_{\text {with } D G}}{\text { TVSI }_{\text {without } D G}}
$$

c) Total Power-Loss Index (TPLI): As the lower active power loss is more appropriate in case of power grid operation, therefore, the total power loss index (TPLI) and its per-unit value are described as follows [4]:

TPLI $=\sum_{\mathrm{j}=1}^{\mathrm{N}_{\mathrm{Y}}} \sum_{\mathrm{t}=1}^{24} \sum_{\mathrm{b}=1}^{\mathrm{N}_{\mathrm{b}}} \mathrm{r}_{\mathrm{b}} \times \mathrm{I}_{\mathrm{j}, \mathrm{t}, \mathrm{b}}{ }^{2}$

$\mathrm{TPLI}_{\text {p.u. }}=\frac{\mathrm{TPLI}_{\text {with }} \mathrm{DG}}{\mathrm{TPLI}_{\text {without }} \mathrm{DG}}$

All material on each page should fit within a rectangle of $18 \mathrm{x}$ $23.5 \mathrm{~cm}$ (7" x 9.25"), centered on the page, beginning $2.54 \mathrm{~cm}$ (1") from the top of the page and ending with $2.54 \mathrm{~cm}(1 ")$ from the bottom. The right and left margins should be $1.9 \mathrm{~cm}$ (.75"). The text should be in two $8.45 \mathrm{~cm}\left(3.33^{\prime \prime}\right)$ columns with a $.83 \mathrm{~cm}(.33 ")$ gutter.

\section{MULTI OBJECTIVE PARTICLE SWARM OPTIMIZATION (MOPSO) BASICS}

\subsection{Selecting the Optimal Solution in Accordance with the DisCo's and the DG Owner's Viewpoints}

As discussed earlier, this problem should be solved using multiobjective methods, such as the MOPSO technique. Therefore, the final result of this optimization method is a Pareto optimal set of non-dominated solutions [23]. To extract the best compromise solution, various methods have been implemented in the literature, such as a fuzzy-based mechanism called a fuzzy Decision-making method which presents a solution to the decision maker [25]. In this paper, a new technique based on economic and operational indices is presented that satisfies both sides of the contract standpoints.

To select an optimal solution, including DGs' size, location, and the contract price, two important issues should be considered: First, in the optimal solution, the profit of the DisCo and the DG owner should be given adequately (based on the DG owner's and DisCo's perspectives). Secondly, the operational condition of the grid, based on the optimal solution, should be at acceptable levels (based on just the DisCo's perspectives).

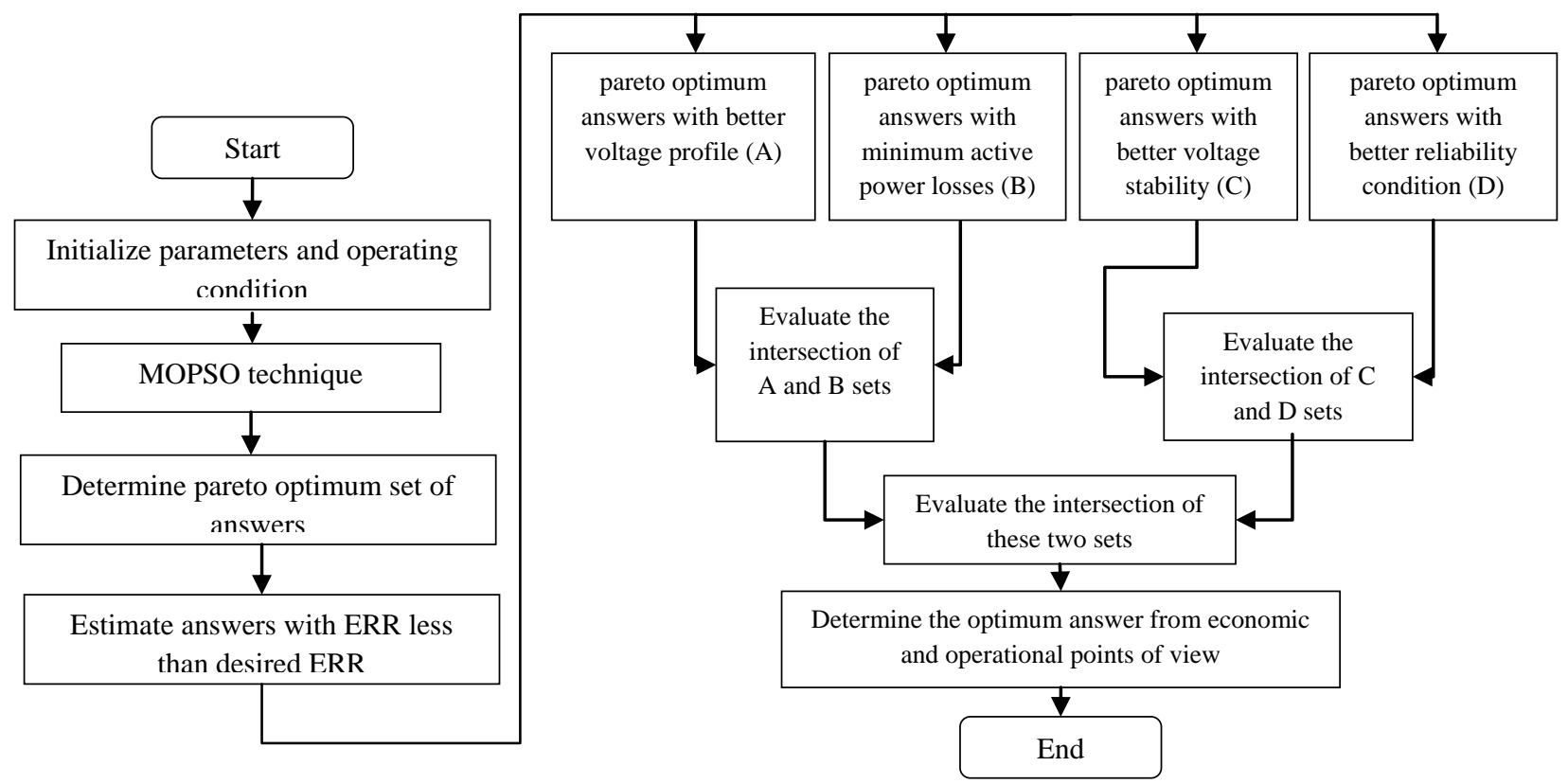

Fig 3: Flowchart of the MOPSO method

It is worthy to note that the operational issues are not directly used in the proposed multiobjective algorithm. Hence, another way must be affected to include the operational factors in our selection technique.

According to the well-defined indices in Section II-D, it will be supposed that the ERR and PP are specified. These values are in accordance with the DG owner's contract; therefore, the values of IRR which are more than the ERR and lower PPs will also be accepted by the DG owner. To encourage the DG owner, it is sensible to remove the Pareto answers with lesser values of IRR or higher values of PP indices from the Pareto set. In this case, the remaining points will be amenable by the DG owner and could be selected from his or her perspectives. After that, the DisCo's viewpoints should be taken into attention in order to have better operational condition for the grid in addition gaining more profit. In the next step, the introduced operational indices will be calculated for each remaining point. In order to have all of the indices in an applicable condition, for each index, the first half of points having better conditions are carefully chosen. Among the intersection of obtained points for all indices, the point with the lowest DisCo's cost will be selected ultimately. Consequently, the DG owner and the DisCo will be satisfied because the DG owner will receive adequate profit, and the DisCo's cost will decrease in comparison to the case without using DGs. Moreover, the operational conditions of the grid will be of better-quality significantly. The flowchart of the algorithm is depicted in Fig. 3

\subsection{Multiobjective Pso}

The multiobjective (MO) format of PSO called MOPSO is suitable in case of minimizing multiple objective functions simultaneously. If $f(x)$ consists of an objective functions, then the multiobjective problem can be defined as finding the vector $x^{*}=\left[x_{1}^{*}, x_{2}^{*} \ldots x_{m}^{*}\right]$ in order to minimize $\mathrm{f}(\mathrm{x})$ $\min f(x)=\left\langle f_{1}(x) f_{2}(x) \ldots f_{n}(x)\right\rangle$ subject to $x^{*} \in \chi$. Generally, 
multiobjective optimization technique results in a set of optimal solutions, rather than having one solution. The reason is that none of the solutions can be considered to be better than any other with respect to all objective functions. Consequently, in the MOPSO method, there is not usually one global optimum, but a set of so-called Pareto-optimal solutions [23]. A decision vector $\mathrm{x} 1$ is called Pareto-optimal if there is no other decision vector $\mathrm{x} 2$ that dominates it. In the minimization problem, the solution $\mathrm{x} 1$ dominates $\mathrm{x} 2$ if
1) $\forall_{i} \in\left\{1,2, \ldots N_{o b j}\right\}: f_{i}\left(x_{1}\right) \leq f_{i}\left(x_{2}\right)$
2) $\exists_{i} \in\left\{1,2, \ldots N_{o b j}\right\}: f_{i}\left(x_{1}\right)<f_{i}\left(x_{2}\right)$

Like PSO, in the MOPSO algorithm, each particle at the time $\mathrm{t}$ is introduced by two borders, its velocity $V_{i}(t)$ and its position $X_{i}(t)$. According to following equations, each vector will be updated at time $(\mathrm{t}+1)$ as below [24]

$$
\begin{aligned}
& V_{i}(t+1)=w(t) V_{i}(t)+c_{1} r_{1}\left(L_{i}(t)-X_{i}(t)\right)+c_{2} r_{2}\left(G_{i}(t)\right. \\
& \left.-X_{i}(t)\right) \\
& X_{i}(t+1)=V_{i}(t)+X_{i}(t)
\end{aligned}
$$

Where $c 1$ and $c 2$ are positive constant coefficients which show the importance of local best and global best, respectively, $r 1$ and $r 2$ and are random numbers. $w(t)$ is inertia weight which helps the algorithm to find the Pareto optimal set more rapidly and is almost always constant. $L_{i}(t)$ and $G_{i}(t)$ are local best and global best which are selected as follows: At first, the non-dominated local set (which contains a position of the non-dominated solution) and non-dominated global set (which contains a position of the non-dominated solution between all members of nondominated local sets) is formed. Then individual distances between members in the non-dominated local set of the particle, and members in the non-dominated global set are measured in the objective space. $\operatorname{Li}(\mathrm{t})$ and $\operatorname{Gi}(\mathrm{t})$ are the members of these sets that give the minimum distance [24]

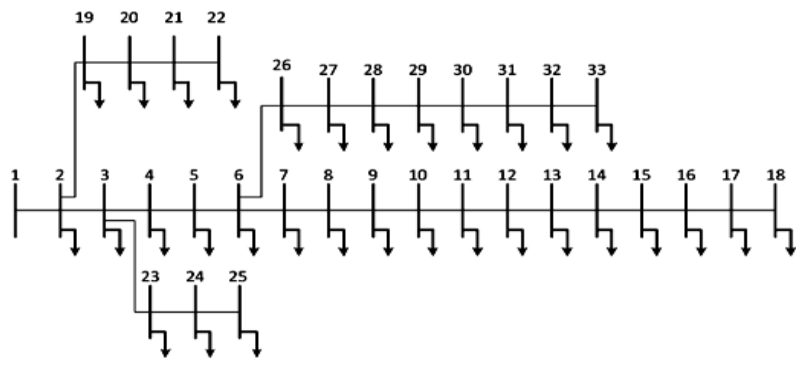

Fig 4: IEEE 33-bus distribution test system

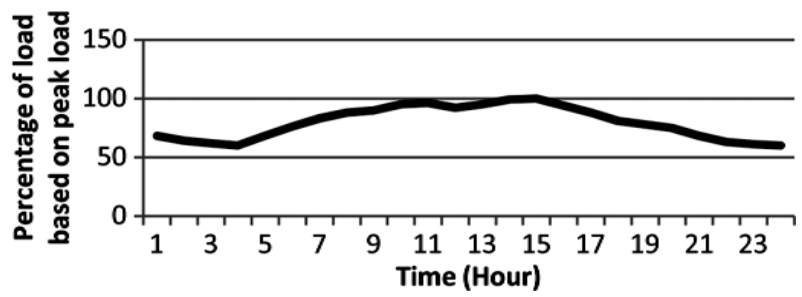

Fig 5: The 24-h variation curve of each bus load based on the peak value

\section{IMPROVED NSGA-II ALGORITHM}

\subsection{Overview of NSGA-II}

NSGA-II uses non-dominated sorting and sharing to search a compromising solution for $\mathrm{MOO}$, and it is an efficient algorithm for a large number of benchmark problems [15].

\subsection{Dominated, Non-dominated, and Pareto-Optimal Set}

MOO can be expressed as follows:

$\min f_{i}(f), \quad i=1,2, \ldots, N_{o b j}, \quad x \in \chi$

Where $\mathrm{f}_{\mathrm{i}}(\mathrm{x})$ denotes the ith objective function, and $\chi$ is the feasible searching space.

Definition 1: A solution $x_{1}$ is said to dominate $x_{2}$ (denoted by $\mathrm{x}_{1}<\mathrm{x}_{2}$ ) if and only if

$$
\begin{aligned}
\forall_{\mathrm{i}}, \quad \mathrm{j} \in\{1,2, \ldots, & \left.\mathrm{N}_{\text {obj }}\right\}, \\
& \exists \mathrm{f}_{\mathrm{i}}\left(\mathrm{x}_{1}\right) \leq \mathrm{f}_{\mathrm{i}}\left(\mathrm{x}_{2}\right) \wedge \mathrm{f}_{\mathrm{j}}\left(\mathrm{x}_{1}\right)<\mathrm{f}_{\mathrm{j}}\left(\mathrm{x}_{2}\right)
\end{aligned}
$$

for $\mathrm{i} \neq \mathrm{j}$

Definition 2: For $S=\left\{x_{i}, i=1, \ldots, n\right\}$, solution is said to be a nondominated solution (Pareto solution) of set $S$ if $x \in S$, and there is no solution $\mathrm{x}^{\prime} \in \mathrm{S}$ for which $\mathrm{x}^{\prime}$ dominates $\mathrm{x}$.

Definition 3: Assume that set P contains all nondominated solutions of $\mathrm{S}$, then

$P F=\left\{v \mid v=\left[f_{1}(x), f_{2}(x), \ldots f_{N_{o b j}}(x)\right]^{T} x \in P\right\}$ is a Pareto front of setS.

\subsection{INSGA-II: Improved Non-dominated Sorting Strategy}

The enhanced sorting strategy simultaneously considers the non-dominated sorting and density information for each instance. Suppose that NP is the population size, it first computes the non-dominated rank for each individual in population using the fast non-dominated sorting strategy to be introduced by NSGA-II; then, it adds its non-dominated rank and the number of individuals that dominate it. The technique is as follows:

$\mathrm{m}\left(\mathrm{X}_{\mathrm{i}}\right)=\mathrm{R}\left(\mathrm{X}_{\mathrm{i}}\right)+\mathrm{n}\left(\mathrm{X}_{\mathrm{i}}\right)$

Where $X_{\mathrm{i}}$ is the ith individual, $\mathrm{R}\left(\mathrm{X}_{\mathrm{i}}\right)$ is the nondominated rank of $X_{i}$, and $n\left(X_{i}\right)$ is the number of individuals to dominate $X_{i}$. Finally, for $i=1,2,3 \ldots, N P$, sorts $m\left(X_{i}\right)$ in ascending order, and assigns the order to $X_{i}$ as the improved rank, i.e.

$\mathrm{R}^{\text {new }}\left(\mathrm{X}_{\mathrm{i}}\right)=$ ascendingOrder $\left\{\mathrm{m}\left(\mathrm{X}_{1}\right), \mathrm{m}\left(\mathrm{X}_{2}\right) \ldots, \mathrm{m}\left(\mathrm{X}_{\mathrm{i}}\right)\right\}$ (36)

Where $\mathrm{R}^{\text {new }}\left(\mathrm{X}_{\mathrm{i}}\right)$ is the improved rank of $\mathrm{X}_{\mathrm{i}}$. It will be as a rank result of improved non-dominated sorting. In order to demonstrate the effect of the INSGA-II, a 2-D objectives optimization problem is taken as an example. It assumes that after fast non-dominated sorting, individuals a e are at the first rank, and individuals $\mathrm{A} \sim \mathrm{C}$ are at the second rank. It also assumed that individual is dominated by individual, $\mathrm{a}, \mathrm{b}$ and $\mathrm{c}$; individual is dominated by individual respectively, which can be shown in Fig. 1. Using the conventional sorting strategy, the individuals $\mathrm{A} \sim \mathrm{C}$ have the same rank. Conversely, the number of their respective adjacent dominating solutions is different. To illustrate the different density corresponding to $\mathrm{A}, \mathrm{B}$ and $\mathrm{C}$, three equal radius circles are displayed to cover the adjacent individuals. 


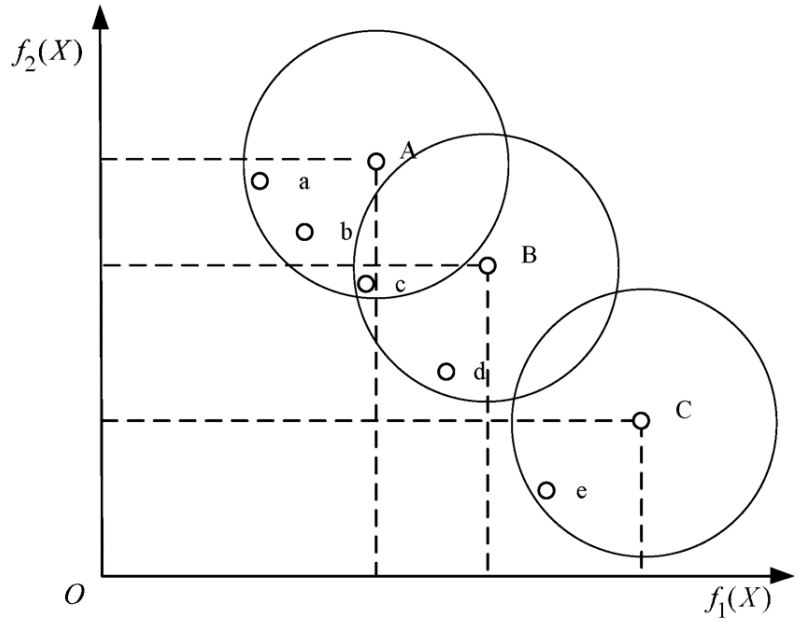

Fig 6: Individual distribution chart

As shown in Fig. 6, individual A is more crowded than B, and individual $\mathrm{B}$ is more crowded than $\mathrm{C}$. Through the improved sorting strategy, the rank of individual A, B and C are 4, 3, and 2, respectively. Therefore, the individual $\mathrm{C}$ that has less density holds the lower rank, which means it has more superiority in the selection process. In this way, the improved sorting strategy is beneficial to maintain better diversity in population.

\subsection{INSGA-II: HAC-Based Truncation Strategy}

The truncation strategy in NSGA-II is shown in Fig. 2. Here, individuals with lower rank can be conserved directly to the next-generation population, until the size of the nextgeneration population overflows if all individuals in certain rank are maintained. According to NSGA-II, individuals in that rank should be sorted using the crowded comparison operator [15] in descending order, and then individuals needed to fill all population slots selected. However, the truncation strategy may abolish the diversity of solutions; namely, it may lead to the uneven distribution. In order to better conserve the diversity and evenly distributed performance in Process 2, a method based on hierarchical agglomerative clustering (HAC) [16] is introduced. In the proposed method, individuals in the truncated rank are grouped into an appropriate number of clusters, and then those with the largest crowding distance in each cluster are conserved to fill population slots. The space distance of solutions is used to measure the similarity of individuals in pair, and the Euclidean distance is used as the distance metric. Taking 2-D objectives optimization problem as one example, as shown in Fig. 6, five individuals need be extracted from candidates $\mathrm{a} \sim \mathrm{i}$ which are all in the same rank. Two steps should be followed to complete the truncation:

Step 1) Use the HAC algorithm to separate all individuals into five clusters $\mathrm{I} \sim \mathrm{V}$.

Step 2) Execute the crowded-comparison operator for each individual and choose the one with the largest crowding distance in each cluster. Then, the individuals $a, b, e, g$, and $i$ are extracted. According to the traditional truncation strategy, individuals $\mathrm{a}, \mathrm{b}, \mathrm{g}, \mathrm{h}$, and $\mathrm{i}$ will be selected Comparing two groups of results, the difference can be noticed that the HACbased truncation strategy chooses individual e but not $\mathrm{h}$ into population slots, which is shown in Fig. 4. In order to describe the evenly distributed performance of the proposed strategy, the coordinates of each individual are illustrated in Fig. 4.
And the variance of distances of adjacent individuals is calculated to measure the even degree. Based on the HACbased truncation strategy, the variance is 0.3528 . For the traditional truncated approach, the variance is 2.1580 . So the proposed improved truncation strategy can make the obtained solutions be evenly distributed with more diversity.

\subsection{INSGA-II: Improved Mutation and Crossover Strategy}

The mutation and recombination strategy [17] in DE optimization is integrated in the proposed INSGA-II algorithm. Detailed operations are described as follows.

1) Mutation Operation: For each $x_{i}(i=1,2, \ldots, N P)$, the weighted difference of two randomly chosen population vectors $x_{r 2}$ and $x_{r 3}$ is added to another randomly selected population member $x_{r 1}$, to form a mutated vector $x^{\prime}$

$x_{i}^{\prime}=x_{r 1}+F \times\left(x_{r 3}-x_{r 2}\right)$

Where $x_{i}^{\prime}$ is the new mutated vector, and is a predefined step size, which is typically chosen from range $[0,2]$. The mutation operation can improve the local search around the current best solution.

2) Recombination Operation: Assuming that the individual $i$ is composed with chromosome vector $x_{i}=\left[u_{i 1}, u_{i 2}, \ldots, u_{i, N C}\right]^{T}$, and the mutated individual is composed with chromosome vector, then the new individual $x^{\prime \prime}{ }_{i}$ is created by (36). The new individual vector is mixed with the original vector $x_{i}$ and mutated vector $x_{i}^{\prime}$ to yield to the new vector $x^{\prime \prime}{ }_{i}$ after the recombination operation

$u^{\prime \prime}{ }_{i, j}=\left\{\begin{array}{l}u_{i, j} \text { if } \operatorname{rand}(j) \geq C R \\ u_{i, j}^{\prime} \text { if } \operatorname{rand}(j)<C R\end{array} j=1,2, \ldots, N C\right.$

Where $\operatorname{rand}(j) \in[0,1]$ and crossover rate $C R \in[0,1], N C$ is the length of the chromosome. The recombination operation can increase the diversity of the perturbed parameter vector.

\subsection{Choosing the Best Compromise Solution via a Fuzzy Decision}

For decision making, it is essential to select a best compromise solution from the obtained MOO solution sets. Here, using the Fuzzy Set Theory determines the best compromise solution. First, the membership function $\tau_{i}^{k}$ of the kth solution for the kth objective function $F_{i}^{k}$ is defined as

$\tau_{\mathrm{i}}^{\mathrm{k}}=\frac{\mathrm{F}_{\mathrm{i}}^{\max }-\mathrm{F}_{\mathrm{i}}^{\mathrm{k}}}{\mathrm{F}_{\mathrm{i}}^{\max }-\mathrm{F}_{\mathrm{i}}^{\min }}$

where $F_{i}^{\max }$ and $F_{i}^{\min }$ are the maximum and minimum of the kth objective function among all nondominated solutions, respectively. Obviously $\tau_{\mathrm{i}}^{\mathrm{k}}$, gives a measure of the satisfaction degree of the kth solution for the kth objective function. Then, using the fuzzy decision determines the best compromise solution $\mathrm{x}^{\mathrm{k} *}$ in the Pareto solution set as

$\mathrm{x}^{\mathrm{k} *}$, and $\bar{\tau}^{\mathrm{k} *}=\max _{\mathrm{k}=1, \ldots, \mathrm{M}}\left\{\frac{\sum_{i=1}^{\mathrm{N}_{\mathrm{obj}}} \tau_{\mathrm{i}}^{\mathrm{k}}}{\sum_{\mathrm{j}=1}^{\mathrm{M}} \sum_{\mathrm{i}=1}^{\mathrm{N}_{\mathrm{obj}}} \tau_{\mathrm{i}}^{\mathrm{j}}}\right\}$

Where $\mathrm{M}$ is the number of Pareto solutions.

\subsection{Complete Algorithm of the INSGA-II Method}

The flowchart of the proposed algorithm is shown in following pseudo-codes. 


\section{Algorithm 1 Procedures of the INSGA-II}

Input: The number of objectives, population size NP, maximal iteration $t_{\text {max }}$, etc.

Output: Optimal solution $x^{k *}$

1: Initialize $P_{0}=\left\{x_{1}, x_{2}, \ldots, x_{N P}\right\}$, and set iteration number $\mathrm{t}=0$.

2: Power flow computation, and compute objective values $\mathrm{f} 1$, f2, F3.

3: while $t<t_{\max }$, do.

4: Make selection, mutation and recombination operations on parent group $P_{t}$, and form $N P / 2$ new individuals as offspring group $Q_{t}$;

5: Power-flow computation, combine current population and offspring group $R_{t}=P_{t} U Q_{t}$

6: Use improved nondominated sorting strategy in $R_{t}$, and form multiple ranks $L=\left\{L_{1}, L_{2} \ldots\right\}$;

7: Truncate the combined population using the HAC-based strategy, and form $P_{t+1}$

$8: t=t+1$

9: end while

10: Get the best comprises solution using the Fuzzy Set Theory;

11: return $x^{k *}$.

\section{EXPERIMENTAL RESULTS}

The multiobjective optimization has been solved using the MOPSO algorithm to obtain the optimum solution that maximizes the DG owner's profit and minimizes the DisCo's cost. As mentioned before, these two objective functions are dependent of each other seriously in a way that the reduction of one of them results in decreasing the other one. Hence, there is more than one optimal point. In order to demonstrate the effectiveness of the MOPSO and INSGA-II algorithm, the optimal DG allocation of the IEEE 33-bus distribution networks with DG are considered and tested. Both the algorithms are developed in MATLAB. In the INSGA-II algorithm, the population number $\mathrm{NP}=200$; the max-iteration number $t_{\max }=100$; the mutation factor $F=0.25$; the crossover factor $C R=0.9$; and the penalty factor, $w_{1} w_{2}$, and $w_{3}$ are all set to 50 .

Table 1. Comparison for the Peak Loading on 33-Bus System with 2-DGS

\begin{tabular}{|c|c|c|c|}
\hline Method & $\begin{array}{c}\text { DG Capacity } \\
\text { (MW) }\end{array}$ & $\begin{array}{c}\text { Line Loss } \\
\text { (KW) }\end{array}$ & $\begin{array}{c}\text { Voltage } \\
\text { Deviation }\end{array}$ \\
\hline $\begin{array}{c}\text { Without } \\
\text { DG }\end{array}$ & --- & 202.6 & 11.7053 \\
\hline NSGA-II & $\begin{array}{c}17-0.5180 \\
32-0.4224\end{array}$ & 104.20 & 3.7420 \\
\hline HPSO & $\begin{array}{c}17-1.7477 \\
32-1.7477\end{array}$ & 65.529 & 5.2041 \\
& \multicolumn{3}{|l}{} \\
\hline
\end{tabular}

Table 2. Result comparison for Light loading of HBPSO and INSGA

\begin{tabular}{|c|c|c|c|}
\hline Method & $\begin{array}{c}\text { No. of } \\
\text { DGs }\end{array}$ & $\begin{array}{c}\text { Total power } \\
\text { Loss(KW) }\end{array}$ & $\begin{array}{c}\text { Voltage } \\
\text { Deviation }\end{array}$ \\
\hline HBPSO & 1 & 16.6000 & 6.10 \\
\hline INSGA & 1 & 9.2486 & 8.18 \\
\hline
\end{tabular}

\begin{tabular}{|c|c|c|c|}
\hline HBPSO & 2 & 27.5256 & 6.00 \\
\hline INSGA & 2 & 9.4377 & 8.18 \\
\hline HBPSO & 3 & 22.7952 & 8.18 \\
\hline INSGA & 3 & 9.2830 & 8.18 \\
\hline HBPSO & 4 & 11.6735 & 8.18 \\
\hline INSGA & 4 & 9.4010 & 8.18 \\
\hline
\end{tabular}

DG units are considered in the modified IEEE 33-bus system shown in Fig. 4. The algorithms were applied to solve this problem. The peak loading data of IEEE 33-bus test system, seen in Table II, are employed as the typical load data. The maximal active power capacities of DG units are set to $1 \mathrm{MW}$.

\section{CONCLUSION}

The final solution for DG allocation and $\mathrm{MOO}$ function values in the IEEE 33-bus system are shown in Table I. MOPSO algorithm to obtain the optimum solution that maximizes the DG owner's profit and minimizes the DisCo's cost in terms of line loss. The, INSGA-II has benefits in finding evenly distributed solutions, and the light loading by INSGA-II has enhanced diversity in selecting the best compromise solution. The computation result is shown in Table I for peak loading. As shown in Table II, two objective function values in the light loading case are smaller than the peak loading cases. The aforementioned experiment result provides evidence that the optimal DG allocation scheme with INSGA-II in peak loading can be feasible in various loading levels. There is the scope to work on the hybrid optimisation techniques with various load flow schemes.

\section{REFERENCES}

[1] C. L. T. Borges and D. M. Falcao, "Impact of distributed generation allocation and sizing on reliability, losses and voltage profile," in Proc. IEEE Power Tech Conf., Bologna, Italy, 2003, vol. 2, pp. 1-5.

[2] IEEE Standard for Interconnecting Distributed Resources with Electric Power systems, IEEE Std. 1547-2003, 2003, pp. 1-16.

[3] T. A. Short, Electric Power Distribution Handbook, 1st ed. Boca Raton, FL: CRC, 2003.

[4] B. A. de Souza and J. M. C. de Albuquerque, "Optimal placement of distributed generators networks using evolutionary programming," in Proc. Transm. Distrib. Conf. Expo.: Latin Amer., 2006, pp.1-6.

[5] N. Acharya, P. Mahat, and N. Mithulananthan, "An analytical approach for DG allocation in primary distribution network," Elect. Power Syst. Res., vol. 28, no. 10, pp. 669-678, Dec. 2006.

[6] Fahad S. Abu-Mouti, Student Member, IEEE, and M. E. El-Hawary, "Optimal Distributed Generation Allocation and Sizing in Distribution Systems via Artificial Bee Colony Algorithm" IEEE Transactions On Power Delivery, Vol. 26, No. 4, October 2011, 2090-2101

[7] M.M. Aman, G.B. Jasmon, A.H.A. Bakar, and H. Mokhlis, "A new approach for optimum simultaneous multi-DG distributed generation Units placement and sizing based on maximization of system loadability using HPSO (hybrid particle swarm optimization) algorithm" Elsevier 18 January 2014, Energy (66) 202-215.

[8] Wanxing Sheng, Ke-Yan Liu,Yuan Liu, Xiaoli Meng, and Yunhua Li, "Optimal Placement and Sizing of Distributed Generation via an Improved Nondominated Sorting Genetic Algorithm II" IEEE Transactions On 
Power Delivery, Vol. 30, No. 2, April 2015

[9] P. Kessel and H. Glavitsch, "Estimating the voltage stability of a power system," IEEE Trans. Power Del., vol. PWRD-1, no. 3, pp. 346-354, Jul. 1986.

[10] G. B. Jasmon and L. H. C. C. Lee, "Distribution network reduction for voltage instability analysis and loadflow calculations," Int. J. Elect. Power Energy Syst., vol. 13, no. 1, pp. 1-3, 1991.

[11] Kennedy J, Eberhart R. Particle swarm optimization. Conference Particle Swarm Optim;4. p. 1942-8.

[12] Nguyen Cong H, Mithulananthan N, Bansal RC. Location and sizing of distributed generation units for loadability enhancement in primary feeder. IEEE Syst $\mathbf{J}$ 2013;7(4):797e806.

[13] Karaboga D. An idea based on honey bee swarm for numerical optimization. Techn Rep TR06. Erciyes:
Erciyes Univ Press; 2005.

[14] Gözel T, Eminoglu U, Hocaoglu MH. A tool for voltage stability and optimization (VS\&OP) in radial distribution systems using matlab graphical user interface (GUI). Simul Model Pract Theory 2008;16(5):505-18.

[15] K. Deb, A. Pratap, S. Agarwal, and T. Meyarivan, "A fast and elitist multiobjective genetic algorithm: NSGAII,” IEEE Trans. Evol. Comput., vol. 6, no. 2, pp. 182 197, Apr. 2002.

[16] T. Hastie, R. Tibshirani, and J. Friedman, The Elements of Statistical Learning, 2nd ed. New York: Springer, 2009.

[17] M. Varadarajan and K. S. Swarup, "Network loss minimization with voltage security using differential evolution," Elect. Power Syst. Res., vol. 78, no. 5, pp. 815-823, 2008. 